\title{
Endoscopic ultrasound-guided fine-needle aspiration of an aortocaval lymph node by the transcaval approach
}

\author{
Narendra S. Choudhary, Rinkesh K. Bansal, Rajesh Puri, Mridula Guleria ${ }^{1}$, Randhir Sud \\ Institute of Digestive and Hepatobiliary Sciences, 'Department of Cytopathology, Medanta, The Medicity, Gurgaon, Haryana, India
}

\begin{abstract}
\end{abstract}
\section{Introduction}

A 59-year-old male was diagnosed as carcinoma gallbladder in October 2014. He underwent radical cholecystectomy; histopathology was suggestive of moderately differentiated adenocarcinoma. The patient received four cycles of chemotherapy. He complained upper abdominal heaviness in December 2015. A positron emission tomography-computed tomography (PET-CT) was done which showed PET-avid $8.5 \mathrm{~mm}$ sized lymph node at aortocaval region. Interventional radiology opinion was taken for fine-needle aspiration (FNA), and no safe route was found. The patient was referred for endoscopic ultrasound (EUS)-guided FNA, and it was found that FNA was not possible without crossing inferior vena cava (IVC) [Figure 1]. The same and risk of bleed was discussed with the patient and oncology team,

Address for correspondence:

Dr. Rajesh Puri, Institute of Digestive and Hepatobiliary Sciences, Medanta, The Medicity, Sector 38, Gurgaon - 122 001, Haryana, India. E-mail: purirajesh70@gmail.com

Access this article online

Website:

www.jdeonline.in

DOI:

$10.4103 / 0976-5042.195769$ and it was decided to take FNA as further management depended on FNA report. The EUS-FNA was done with

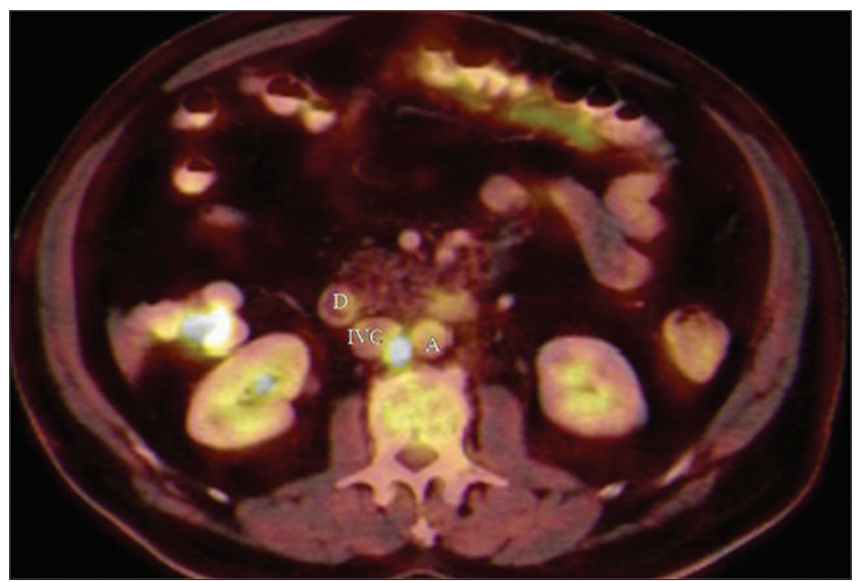

Figure 1: Positron emission tomography-computed tomography image showing intensely fluorodeoxyglucose-avid lymph node in between (posterior to) inferior vena cava (labeled IVC) and aorta (labeled as A), duodenum is labeled as D

This is an open access article distributed under the terms of the Creative Commons Attribution-NonCommercial-ShareAlike 3.0 License, which allows others to remix, tweak, and build upon the work non-commercially, as long as the author is credited and the new creations are licensed under the identical terms.

For reprints contact: reprints@medknow.com

How to cite this article: Choudhary NS, Bansal RK, Puri R, Guleria M, Sud R. Endoscopic ultrasound-guided fine-needle aspiration of an aortocaval lymph node by the transcaval approach. J Dig Endosc 2016;7:158-9. 


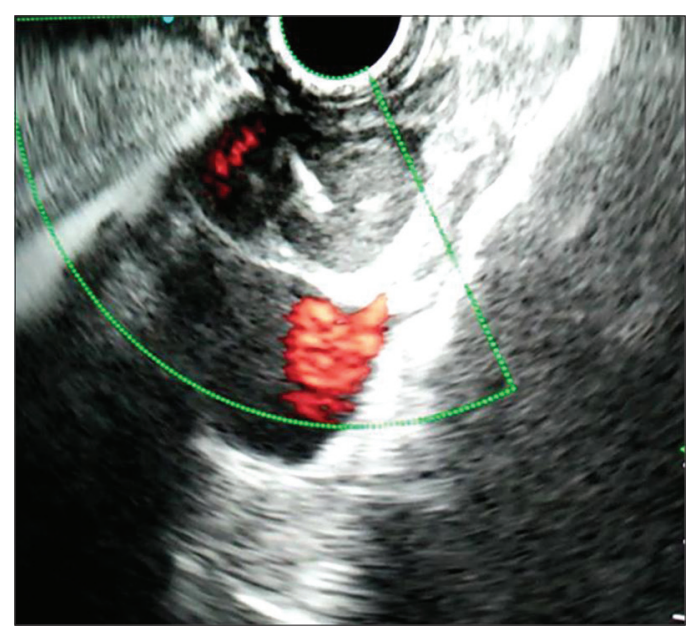

Figure 2: Endoscopic ultrasound image showing needle in lymph node, transversing inferior vena cava

25-gauge needle (Wilson-Cook Medical) without fanning using GF-UCT 140 linear echoendoscope (EUS scope, Olympus, Tokyo, Japan); a single pass was made [Figure 2]. The lymph node was heteroechoic with predominant hypoechoic, round, well-defined border, and size of $8 \mathrm{~mm}$. There was no perilesional hematoma/bleed, and the patient remained asymptomatic. The cytopathological smears were consistent with metastatic adenocarcinoma [Figure 3].

While transaortic EUS-guided FNA has been reported, ${ }^{[1]}$ transvenous FNA has not been reported. Veins have thin walls (unlike arteries), and there is risk of bleed. However, CT-guided transvenous biopsies have been reported. Sofocleous et al.$^{[2]}$ published their experience of 58 biopsies in pancreatic or peripancreatic masses crossing IVC $(n=54) /$ renal vein $(n=4)$ or both $(n=3)$. The authors found CT evidence of perilesional blood in eight patients including three patients where renal artery was punctured. All patients remained asymptomatic. ${ }^{[2]}$ Gupta et al. ${ }^{[3]}$ reviewed CT-guided fine-needle aspiration biopsy using posterior transcaval route in 29 patients and reported minor complications in four patients (small retroperitoneal

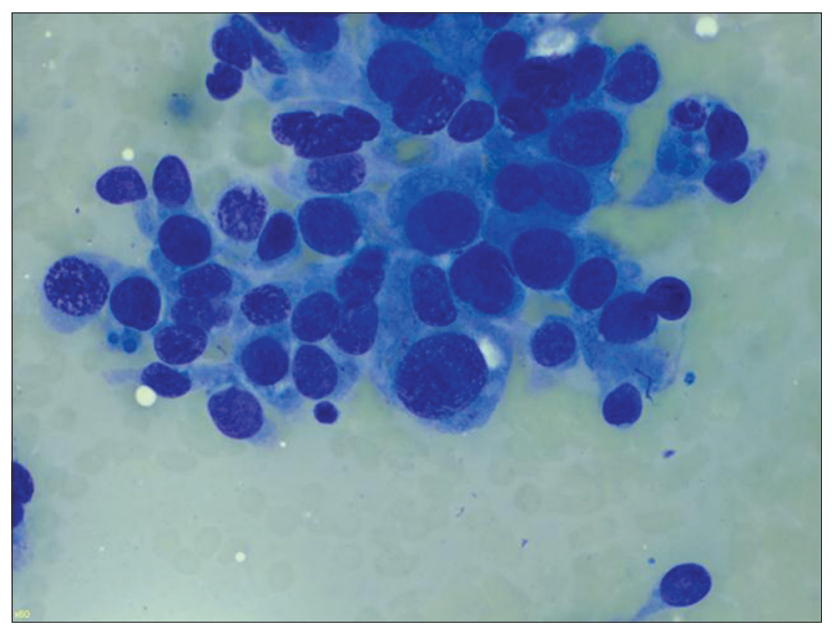

Figure 3: Cytopathological smear (Giemsa stain, $\times 60$ times magnification) showing malignant cells with high $\mathrm{NC}$ ratio

hematomas in three and abdominal pain occurred in one). We suggest that when FNA is necessary and it is not possible to get tissue diagnosis by other means, trans-IVC FNA can be attempted.

\section{Financial support and sponsorship} Nil.

\section{Conflicts of interest}

There are no conflicts of interest.

\section{References}

1. von Bartheld MB, Rabe KF, Annema JT. Transaortic EUS-guided FNA in the diagnosis of lung tumors and lymph nodes. Gastrointest Endosc 2009;69:345-9.

2. Sofocleous CT, Schubert J, Brown KT, Brody LA, Covey AM, Getrajdman GI. CT-guided transvenous or transcaval needle biopsy of pancreatic and peripancreatic lesions. J Vasc Interv Radiol 2004;15:1099-104.

3. Gupta S, Ahrar K, Morello FA Jr., Wallace MJ, Hicks ME. Masses in or around the pancreatic head: CT-guided coaxial fine-needle aspiration biopsy with a posterior transcaval approach. Radiology 2002;222:63-9. 